\title{
Antifertility and Antioxidant Activities of Ethanolic Extract of Leonotis nepetifolia in Male Albino Rats
}

\author{
B Kadalmani ${ }^{1}$, R Niranjana ${ }^{2}$, Uma A Natarajan ${ }^{3}$, I Sarath Chandiran ${ }^{4}$
}

\begin{abstract}
Background and objective: This study based on the antifertility action of Leonotis nepetifolia ethanol extract (whole plant) in the animal model male Wistar Albino rats. Leonotis nepetifolia is reported to have antioxidant activity, antiproliferative potential, hypotensive potential, antiinflammatory, antiplasmodial, antibacterial, antifungal, analgesic, anticancer, laxative and narcotic activities. The plant aids in the recovery of malaria, diarrhea, bronchial asthma, common cold, cough, and fever, particularly used during menstrual pain.

Materials and methods: The animals were grouped into four with five rats each. Control group (group l) received normal saline. The other three groups of rats were treated with the specified dose (group II-100 mg/kg, group III-150 mg/kg, and group III-200 mg/kg) of Leonotis nepetifolia ethanolic extract for a period of 55 days.

Results: A marked reduction in the weight of accessory sex organs/testis, sperm count, and sperm motility were observed in the treated groups. Serum hormonal levels and few biochemical parameters also showed variation compared to the control group. The reports revealed that the treated adult male rats had decreased the counts of female's impregnation.
\end{abstract}

Conclusion: Hence, this current research concluded that L. nepetifolia ethanolic extract (whole plant) repressed sperm motility, concentration, and the testosterone proving dose-dependent antifertility effect.

Keywords: Antifertility, Impregnation, Leonotis nepetifolia, Motility, Sperm count.

SBV Journal of Basic, Clinical and Applied Health Science (2020): 10.5005/jp-journals-10082-02263

\section{INTRODUCTION}

India being a developing country is still not able to cope up with the demerits of having high population. There are a large number of devices, mechanisms, and techniques adopted for antifertility treatment. ${ }^{1}$ Moreover, increasing number of births has got a deleterious effect on social and economic progress. ${ }^{2}$ And on the other hand growth and control of population is an important issue as it is directly proportional to country's life-supporting systems. ${ }^{3}$ The World Health Organization recommended traditional medicine for the antifertility effect as an alternate to synthetic drugs due to its cost-effectiveness in the control of birth. ${ }^{4}$ Leonotis nepetifolia is a short-lived perennial plant belonging to Lamiaceae family found all over the world, especially tropical Africa and southern India. The whole plant is used for the menstrual pain and unspecified female complaints. It is reported to have antioxidant, antiproliferative potential, hypotensive potential, anti-inflammatory, antiplasmodial, antibacterial, antifungal, analgesic, anti-cancer, hypotensive, laxative, and narcotic activities. The plant is also used in traditional medicine for bronchial asthma, diarrhea, fever, malaria, and as an analgesic agent in menstrual pain. It also used to treat common cold and alleviate cough. ${ }^{5}$ The aim of this current research work was to determine the antifertility effect of $L$. nepetifolia ethanolic extract in Wistar albino rats.

\section{Materials and Methods \\ Collection/Identification of Plant}

The well-grown whole plant of L. nepetifolia was collected from Kalakadu, Tirunelveli District, Tamil Nadu. The collected plants were identified using Botanical Survey of India, Coimbatore. The whole plant of $L$. nepetifolia was shade dried and powdered using grinder. The fresh finely ground powder was subjected to

\footnotetext{
${ }^{1,2}$ Department of Animal Science, Bharathidasan University, Tiruchirappalli, Tamil Nadu, India

${ }^{3}$ Genetic Unit, Department of Anatomy, Mahatma Gandhi Medical College and Research Institute, Sri Balaji Vidyapeeth (Deemed to be University), Puducherry, India

${ }^{4}$ School of Pharmacy, Sri Balaji Vidyapeeth (Deemed to be University), Puducherry, India
}

Corresponding Author: I Sarath Chandiran, School of Pharmacy, Sri Balaji Vidyapeeth (Deemed to be University), Puducherry, India, Phone: +91 9489400277, e-mail: bahoursarath@gmail.com

How to cite this article: Kadalmani B, Niranjana R, Natarajan UA, Chandiran IS. Antifertility and Antioxidant Activities of Ethanolic Extract of Leonotis nepetifolia in Male Albino Rats. J Basic Clin Appl Health 2020;3(3):115-121.

Source of support: Department of Animal Science, Bharathidasan University extended under DST-FIST, DST-PURSE scheme.

Conflict of interest: None

extraction in a Soxhlet apparatus using ethanol. The quantitative analytical tests were done on recently prepared extract to identify the phytochemical constituents using standard procedures ${ }^{6}$ and then concentrated using rotatory evaporator for further studies.

\section{Animal Studies}

Male Wistar Albino rats weighing 160-250 g were maintained under controlled conditions of temperature, humidity, and 12-hour light-dark cycles. All the animals were acclimatized for 7 days before the study. The animals were housed in sanitized polypropylene cages containing sterile paddy husk as bedding. They had free access to standard pellets as basal diet and water ad libitum. 
The initial body weight of the animals was recorded. The acute toxicity test was carried out per OECD guidelines 423 . The animals were observed for gross behavior changes as well as for motility for 14 days.

\section{Experimental Design}

The animals were equally divided into four groups (5/group). Group I animals were given normal saline for 55 days and served as control group. Groups II, III, and IV animals received ethanolic extract at oral dose of 100,150, and $200 \mathrm{mg} / \mathrm{kg}$ body weight, respectively, for 55 days. Final weight of the animals was measured/recorded, and blood samples were also collected after 24 hours of last treatment. Then, the animals were sacrificed. The serum were collected separately from blood by centrifugation $(3,000 \mathrm{~g} / 10$ minutes) and stored at $-20^{\circ} \mathrm{C}$. Then, the ventral prostrate, testes, vas deferens, epididymis, and seminal vesicle were dissected, trimmed, weighed, and fixed in 10\% formalin for further analysis.

\section{Determination of Sperm Count}

Sperm count was carried out by using Neubauer's hemocytometer after collecting the epididymal fluid. The procedure was carried out per Lawerence et al. The sperms' viability was determined by AO/ EB staining method.,

\section{Determination of Hematological Parameters}

The blood sample collected was tested for red blood cell count (RBC), white blood cell count (WBC), platelets, and hemoglobin using Neubauer counting chamber.

\section{Assay Procedure for Hormone Detection}

The stored serum was used to measure the level of folliclestimulating hormone (FSH), testosterone, and luteinizing hormone (LH) by enzyme immunoassay method.

\section{Estimation of Biochemical Profile}

The biochemical assays of alanine aminotransferase (ALT/GPT), alkaline phosphatase (ALP), and aspartate aminotransferase(AST/ GOT) were analyzed. ${ }^{9-11}$

\section{Estimation of Oxidative Parameters}

The oxidative parameters such as catalases (CAT), superoxide dismutase (SOD), glutathione peroxidase, and reduced glutathione were analyzed in homogenates of liver, kidney, and testis. ${ }^{12-15}$ Cholesterol and triglycerides levels of the samples were measured using standard procedures. ${ }^{16}$

\section{Histopathology of Testis}

The testis fixed in $10 \%$ formalin were entrenched in paraffin, sectioned using microtome, and subjected to hematoxylin and eosin staining per procedure of Kadalmani et al. ${ }^{17}$

\section{Fertility Test}

Male rat and virgin untreated females (same strain) were positioned in a separate cage in the ratio of 1:2 (male:female) and kept together for 16 days. At the end of 16 days, the male rats were detached and the pregnant female rats were sacrificed. The parameters, namely, number of pregnant rats, implantation sites, and fetus numbers, were recorded. $^{18}$

\section{Statistical Analysis}

All data for control and experimental groups were subjected to statistical evaluation using analysis of variance (ANOVA) for
Table 1: Preliminary phytochemical screening

\begin{tabular}{cll}
\hline & Secondary metabo- & \\
S.no & lites & Result \\
\hline 1 & Steroids & Present \\
2 & Triterpenoids & Absent \\
3 & Alkaloids & Present \\
4 & Phenolic compounds & Absent \\
5 & Flavonoids & Present \\
6 & Reducing sugars & Present \\
7 & Sugars & Absent \\
8 & Catechins & Absent \\
9 & Saponins & Absent \\
10 & Tannins & Present \\
11 & Anthroquinone & Absent \\
12 & Amino acids & Absent \\
\hline
\end{tabular}

significant differences between the controls and experimental groups at $p$ value $<0.05$. All data were recorded systematically in preformed data collection sheet. Statistical analysis was performed by using SPSS for windows version 16.0, and 95\% confidence limit was obtained.

\section{Results}

The phytochemical screening of ethanolic extract of L. nepetifolia whole plant revealed the presence of steroids, alkaloids, flavonoids, reducing sugars, and tannins as shown in Table 1 and Figure 1. The nontoxic nature of the $L$. nepetifolia ethanol extract was proved by the acute toxicity study. The reduction in the final body weight and sex organs, namely, seminal vesicle, vas deferens testis, prostate, and epididymis, were observed in all three treatment groups when compared to the control group (Table 2).

A substantial decrease in the sperm count and presence of abnormal sperm in caudal and caput was noticed in all three treated groups when compared to control group as tabulated in Table 3. Nearly more than half the total percentage of the sperm exhibited abnormal morphologies of different kinds, which encompassed DNA-damaged sperm, broken head, coiled tail area, etc. along with reduction in epididymal sperm concentration and motility (Figs 2 and 3).

The hematological parameters such as platelets, RBC, PCV, and hemoglobin of $L$. nepetifolia-extract treated rats showed significant changes when compared to control and are presented in Table 4. Reduction in serum testosterone, LH, and FSH levels were witnessed in all the three treated groups when compared to group I. The respective levels in groups II, III, and IV were reduced when compared to the group I. Most significance reduction of serum testosterone, $\mathrm{LH}$, and FSH levels were observed the dose of $200 \mathrm{mg} / \mathrm{kg} / \mathrm{bw}$ (Table 5). The serum biochemical parameters such as AST, ALT, and ALP of L. nepetifolia extract treated rats was significantly decreased when compared to control as shown in Figures 4 to 6 , respectively.

The activities of antioxidants CAT, SOD, GPx, and GSH in the tissue homogenates of liver, kidney, and testis of group I and all other treated groups are shown in Figures 7 to 10. In this current research work, ethanolic extract-treated rat indicated suppressed effects of all the antioxidants when compared to group I. Administration of L. nepetifolia extract at the dose of 100, 150 , and $200 \mathrm{mg} / \mathrm{kg}$ showed significant increase in triglyceride 

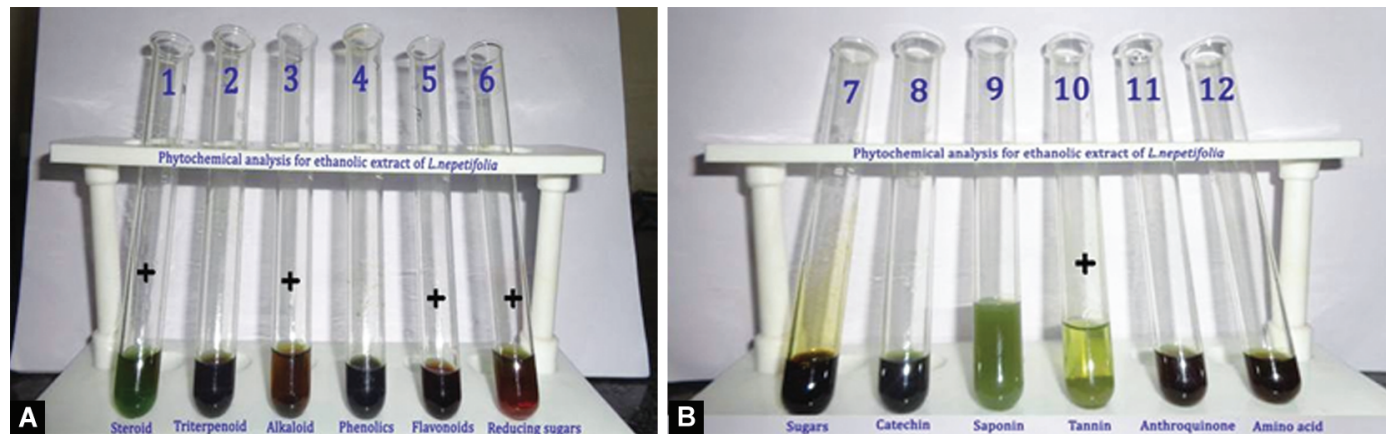

Figs $1 \mathrm{~A}$ and B: Preliminary phytochemical screening

Table 2: Effect of ethanolic extract of Leonotis nepetifolia on body weight and reproductive organ weight

\begin{tabular}{|c|c|c|c|c|c|c|c|}
\hline \multirow[b]{2}{*}{ Groups } & \multirow[b]{2}{*}{ Treatments } & \multicolumn{2}{|c|}{ Body weights (g) } & \multicolumn{4}{|c|}{ Reproductive organ weights (g) } \\
\hline & & Initial & Final & Testis & Epididymis & Seminal vesicles & Prostate gland \\
\hline Group I & Saline & $200 \pm 15.81$ & $192 \pm 8.36$ & $2.2 \pm 0.03$ & $0.67 \pm 0.02$ & $0.45 \pm 0.02$ & $0.27 \pm 0.01$ \\
\hline Group II & L. nepetifolia (100 mg/kg) & $184 \pm 8.94$ & $160 \pm 15.8$ & $1.45 \pm 0.02$ & $0.45 \pm 0.01$ & $0.41 \pm 0.01$ & $0.27 \pm 0.01$ \\
\hline Group III & L. nepetifolia (150 mg/kg) & $206 \pm 8.94$ & $184 \pm 20.7$ & $1.37 \pm 0.04$ & $0.33 \pm 0.02$ & $0.37 \pm 0.01$ & $0.23 \pm 0.01$ \\
\hline Group IV & L. nepetifolia (200 mg/kg) & $250 \pm 10.0$ & $234 \pm 27.0$ & $1.15 \pm 0.02$ & $0.24 \pm 0.03$ & $0.32 \pm 0.02$ & $0.22 \pm 0.02$ \\
\hline
\end{tabular}

Values represent the mean \pm SD of the observation made on five rats in each group. Statistical analysis one-way analysis of variance (ANOVA) with ad hoc testing least significant difference

Table 3: Effect of ethanolic extract of Leonotis nepetifolia on sperm concentration, motility and abnormality

\begin{tabular}{|c|c|c|c|c|}
\hline \multirow[b]{2}{*}{ Treatment } & \multicolumn{2}{|c|}{ Total sperm count } & \multirow[b]{2}{*}{ Sperm motility } & \multirow{2}{*}{$\begin{array}{l}\text { Abnormal sperm } \\
\text { morphology }\end{array}$} \\
\hline & Head & Tail & & \\
\hline Control & $97.34 \pm 3.78$ & $93.24 \pm 3.09$ & $98.76 \pm 6.32$ & $3.98 \pm 0.23$ \\
\hline 100 mg/kg & $74.61 \pm 10.31$ & $71.57 \pm 9.76$ & $74.43 \pm 9.78$ & $32.65 \pm 7.65$ \\
\hline 150 mg/kg & $51.23 \pm 12.79$ & $55.12 \pm 11.47$ & $56.51 \pm 14.78$ & $39.07 \pm 6.54$ \\
\hline 200 mg/kg & $35.17 \pm 7.15$ & $33.78 \pm 7.09$ & $34.23 \pm 7.64$ & $55.34 \pm 7.02$ \\
\hline
\end{tabular}

Values represent the mean \pm SD of the observation made on five rats in each group. Statistical analysis one-way analysis of variance (ANOVA) with ad hoc testing least significant difference

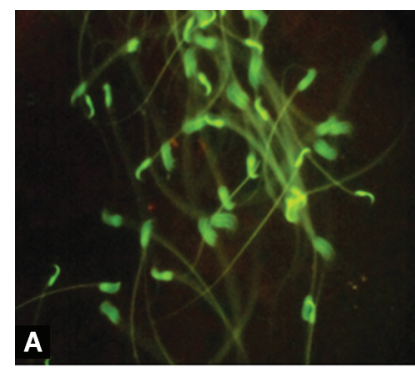

Normal sperm

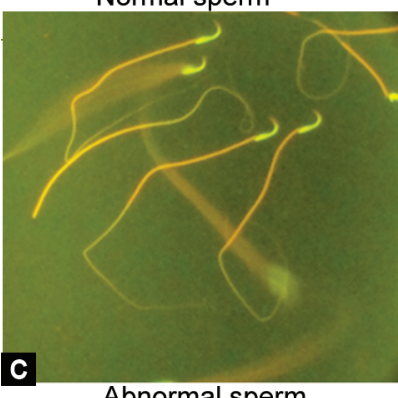

Abnormal sperm

Figs 2A to D: Effect of ethanolic extract of Leonotis nepetifolia on AO/ EtBr staining of sperm morphology

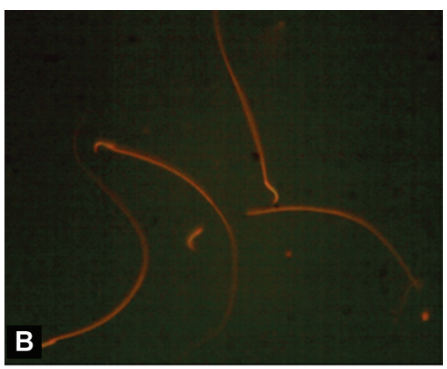

Abnormal sperm

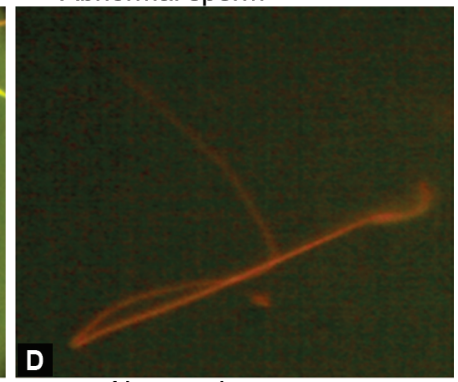

Abnormal sperm

c

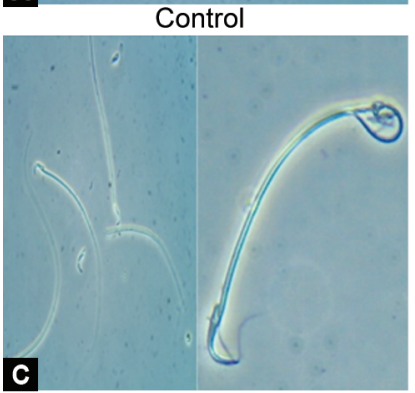

$150 \mathrm{mg} / \mathrm{kg}$

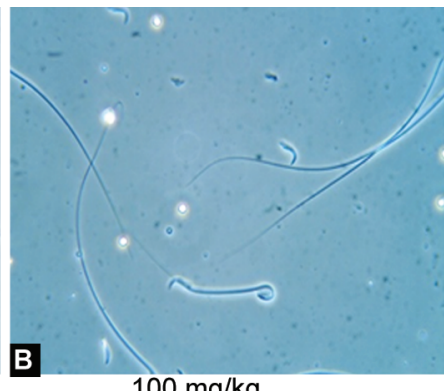

$100 \mathrm{mg} / \mathrm{kg}$

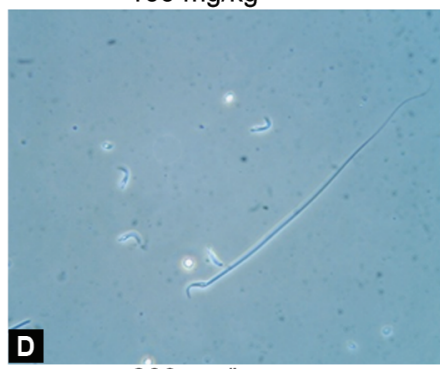

$200 \mathrm{mg} / \mathrm{kg}$

Figs $3 A$ to D: Effect of ethanolic extract of Leonotis nepetifolia on light microscopic observation of sperm morphology 
Table 4: Effect of ethanolic extract of Leonotis nepetifolia on hematological parameters

\begin{tabular}{llllllll}
\hline & & \multicolumn{2}{c}{ Differential count } & Platelet (lakhs) & RBC (million/ \\
S.no. & Groups & $L(\%)$ & $E(\%)$ & cu.mm) & Cu.mm) & PCV (\%) & Hemoglobin \\
\cline { 2 - 7 } & Group I & $57.06 \pm 0.07$ & $3.12 \pm 0.07$ & $4.03 \pm 0.04$ & $1.50 \pm 0.34$ & $61.34 \pm 0.21$ & $20.37 \pm 0.19$ \\
2 & Group II & $46.04 \pm 0.06$ & $3.06 \pm 0.02$ & $3.04 \pm 0.04$ & $6.46 \pm 0.34$ & $59.32 \pm 0.19$ & $19.56 \pm 0.20$ \\
3 & Group III & $43.16 \pm 0.10$ & 3.0240 .03 & $2.4 \pm 0.22$ & $6.28 \pm 0.24$ & $56.21 \pm 0.11$ & $18.42 \pm 0.28$ \\
4 & Group IV & $37.08 \pm 0.06$ & 2.0380 .04 & $1.58 \pm 0.24$ & $5.48 \pm 0.36$ & $53.30 \pm 0.25$ & $17.48 \pm 0.35$ \\
\hline
\end{tabular}

Values represent the mean \pm SD of the observation made on five rats in each group. Statistical analysis one-way analysis of variance (ANOVA) with ad hoc testing least significant difference

Table 5: Effect of ethanolic extract of Leonotis nepetifolia on LH, FSH and testosterone

\begin{tabular}{llllc}
\hline Groups & Treatments & FSH & LH & Testosterone \\
\hline Group I & Saline & $8.16 \pm 0.27$ & $1.69 \pm 0.15$ & $4.52 \pm 0.17$ \\
Group II & L. nepetifolia $100 \mathrm{mg} / \mathrm{kg}$ & $8.13 \pm 0.43$ & $1.29 \pm 0.13$ & $4.02 \pm 0.19$ \\
Group III & L. nepetifolia $150 \mathrm{mg} / \mathrm{kg}$ & $8.10 \pm 0.39$ & $1.09 \pm 0.14$ & $3.36 \pm 0.20$ \\
Group IV & L.nepetifolia $200 \mathrm{mg} / \mathrm{kg}$ & $7.95 \pm 0.35$ & $0.97 \pm 0.09$ & $1.84 \pm 0.24$ \\
\hline
\end{tabular}

Values represent the mean \pm SD of the observation made on five rats in each group. Statistical analysis one way analysis of variance (ANOVA) with ad hoc testing least significant difference

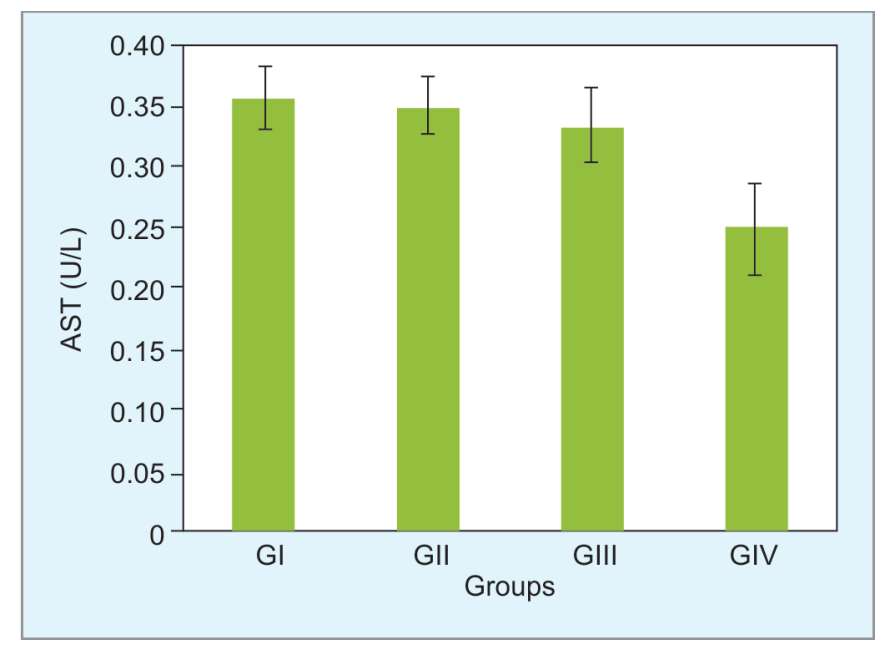

Fig. 4: Effect of ethanolic extract of Leonotis nepetifolia on AST values represents the mean \pm SD of the observation made on five rats in each group. Statistical analysis by one-way analysis of variance (ANOVA) with ad hoc testing least significant difference

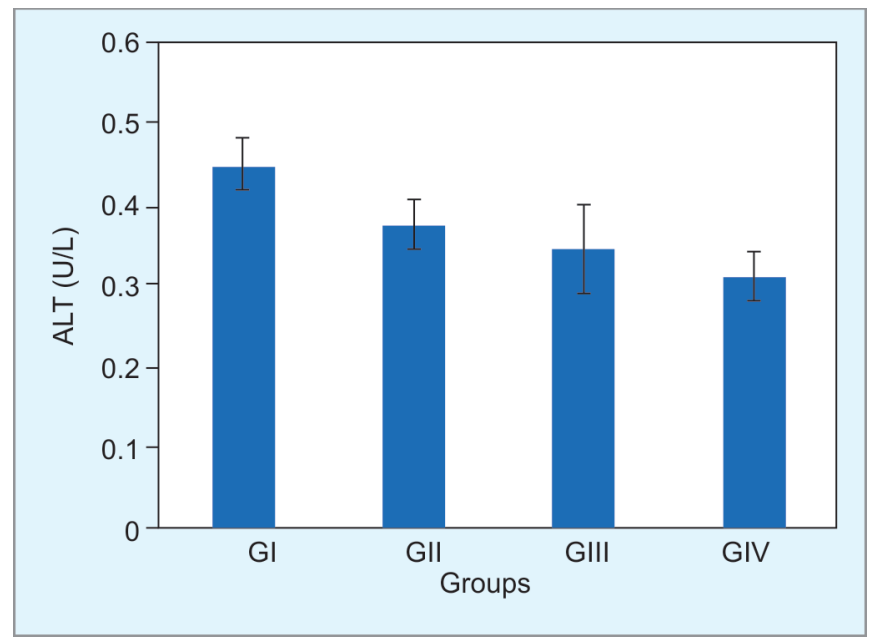

Fig. 5: Effect of ethanolic extract of Leonotis nepetifolia on ALT values represents the mean $\pm S D$ of the observation made on five rats in each group. Statistical analysis by one-way analysis of variance (ANOVA) with ad hoc testing least significant difference

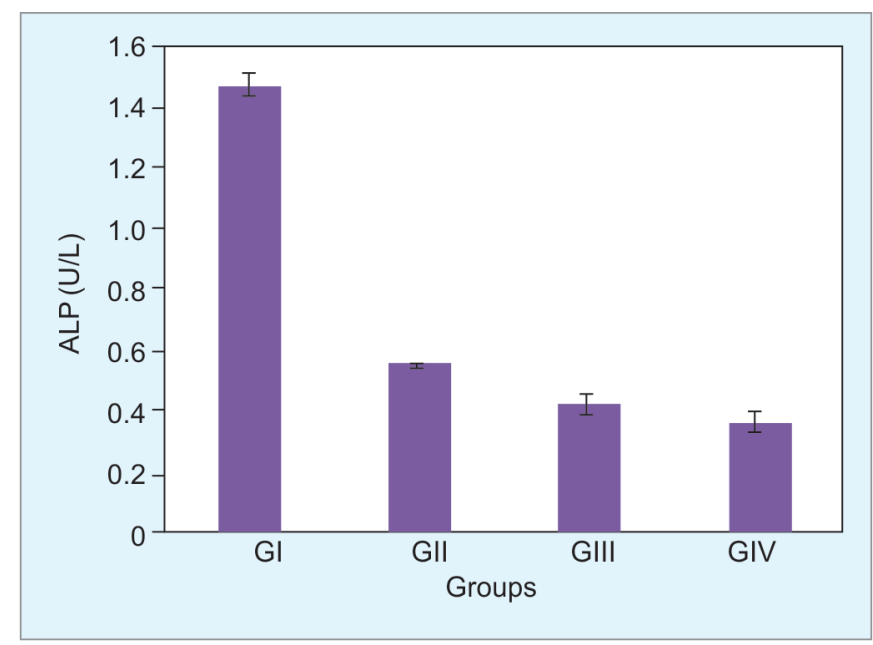

Fig. 6: Effect of ethanolic extract of Leonotis nepetifolia on ALP values represents the mean $\pm S D$ of the observation made on five rats in each group. Statistical analysis by one-way analysis of variance (ANOVA) with ad hoc testing least significant difference 


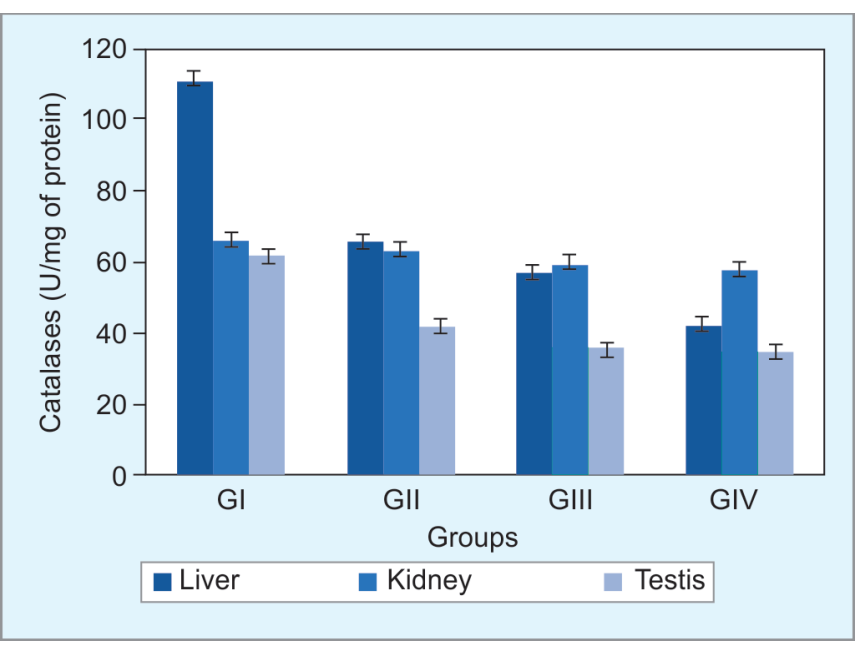

Fig. 7: Effect of ethanolic extract of Leonotis nepetifolia on catalase values represents the mean \pm SD of the observation made on five rats in each group. Statistical analysis by one-way analysis of variance (ANOVA) with ad hoc testing least significant difference

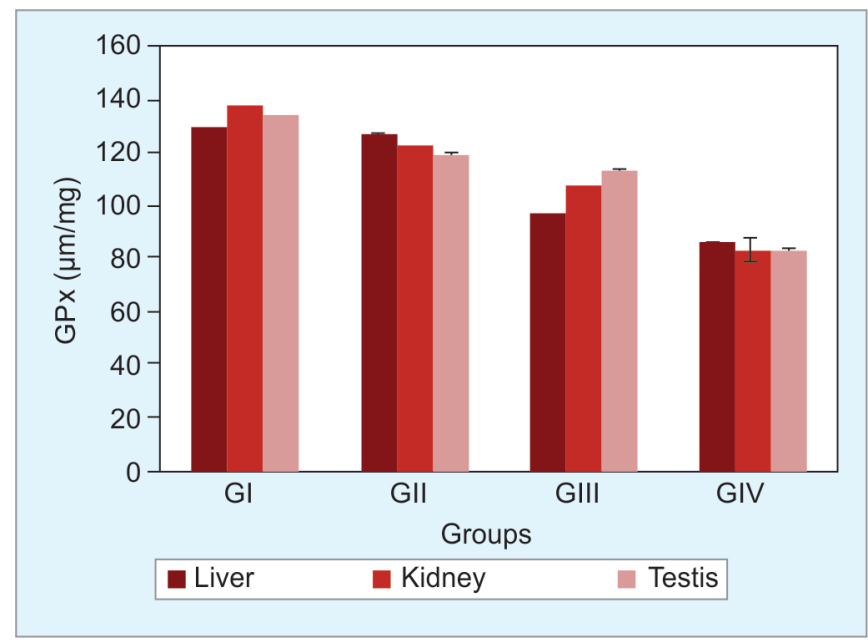

Fig. 9: Effect of ethanolic extract of Leonotis nepetifolia on GPx values represents the mean \pm SD of the observation made on five rats in each group. Statistical analysis by one-way analysis of variance (ANOVA) with ad hoc testing least significant difference

Table 6: Effect of ethanolic extract of Leonotis nepetifolia on cholesterol and triglycerides

\begin{tabular}{llll}
\hline Groups & Treatments & $\begin{array}{l}\text { Cholesterol } \\
(\mathrm{mg} / \mathrm{dL})\end{array}$ & $\begin{array}{l}\text { Triglycerides } \\
(\mathrm{mg} / \mathrm{dL})\end{array}$ \\
\hline Group I & Saline & $147.34 \pm 0.02$ & $0.24 \pm 0.10$ \\
Group II & L. nepetifolia $100 \mathrm{mg} / \mathrm{kg}$ & $166.05 \pm 0.03$ & $0.67 \pm 0.09$ \\
Group III & L. nepetifolia $150 \mathrm{mg} / \mathrm{kg}$ & $171.95 \pm 0.02$ & $0.87 \pm 0.78$ \\
Group IV & L. nepetifolia $200 \mathrm{mg} / \mathrm{kg}$ & $209.34 \pm 0.02$ & $1.23 \pm 0.06$ \\
\hline
\end{tabular}

Values represents the mean \pm SD of the observation made on five rats in each group. Statistical analysis one way analysis of variance (ANOVA) with ad hoc testing least significant difference

and total cholesterol of all groups, compared to the control in a dose-dependent manner. Total cholesterol and triglyceride levels were significantly higher in group treated with $200 \mathrm{mg} / \mathrm{kg} / \mathrm{bw}$ of L. nepetifolia, whereas the total cholesterol ratio was significantly decreased compared to group I (Table 6).

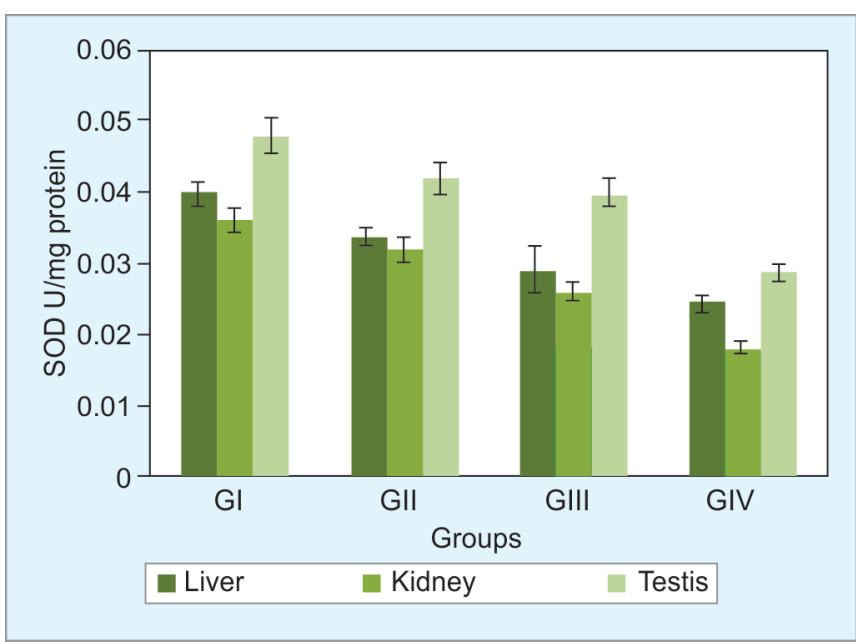

Fig. 8: Effect of ethanolic extract of Leonotis nepetifolia on SOD values represents the mean $\pm S D$ of the observation made on five rats in each group. Statistical analysis by one-way analysis of variance (ANOVA) with ad hoc testing least significant difference

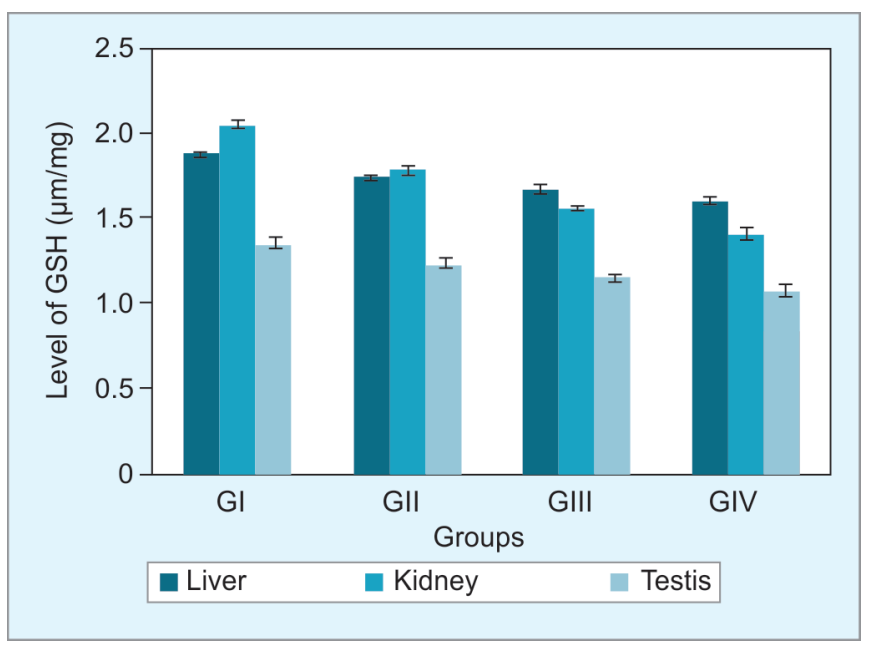

Fig. 10: Effect of ethanolic extract of Leonotis nepetifolia on GSH values represents the Mean \pm SD of the observation made on five rats in each group. Statistical analysis by one-way analysis of variance (ANOVA) with ad hoc testing least significant difference

Leonotis nepetifolia ethanolic extract at $100 \mathrm{mg} / \mathrm{kg}$ presented minor changes such as degeneration of seminiferous tubules along with interstitial edema. On the other hand, group I (control) animal's testicular section represented undamaged Sertoli cells/ basement membrane, complete lumen of seminiferous tubule, and unharmed leydig, interstitial tissue, and peritubular venules/ capillaries. Necrosis of the Sertoli cell was also well observed. Moderate to severe degeneration of the seminiferous tubules and shrinkage for rats treated with 150 and $200 \mathrm{mg} / \mathrm{kg} / \mathrm{bw}$ L. nepetifolia ethanolic extract are also indicated in Figure 11. The results shown in Table 7 revealed a dose-dependent reduction in the number of pregnant females and number of implantation.

\section{Discussion}

Based on the extensive use of herbal medicines, many research works have been assumed to determine the welfare and efficiency of traditional therapies. The current study was undertaken to 

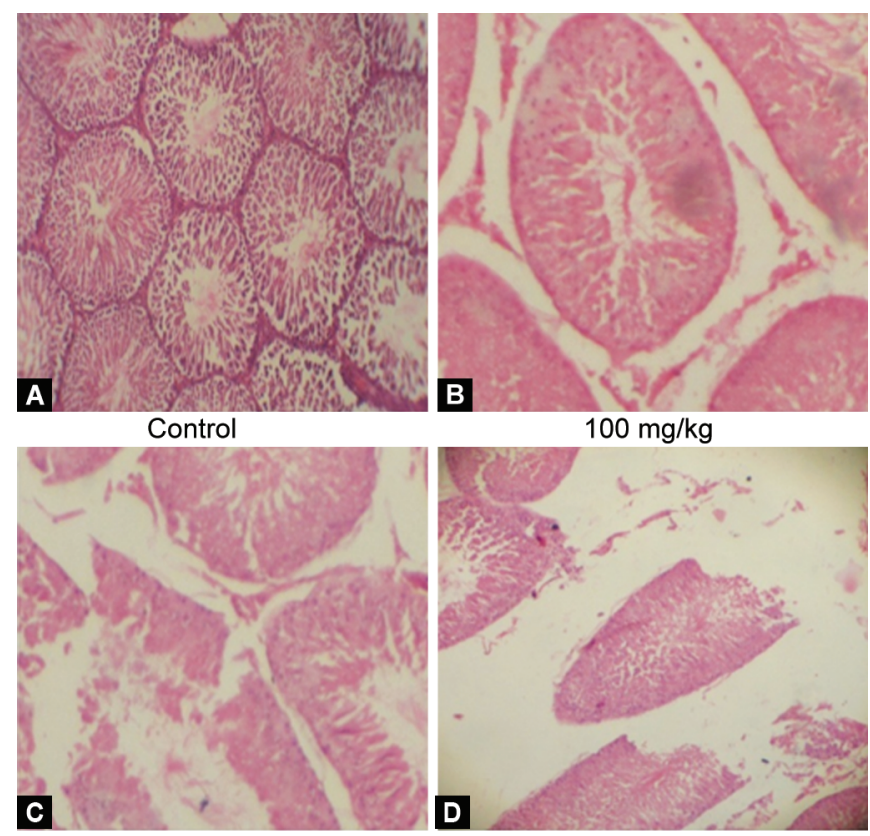

$150 \mathrm{mg} / \mathrm{kg}$

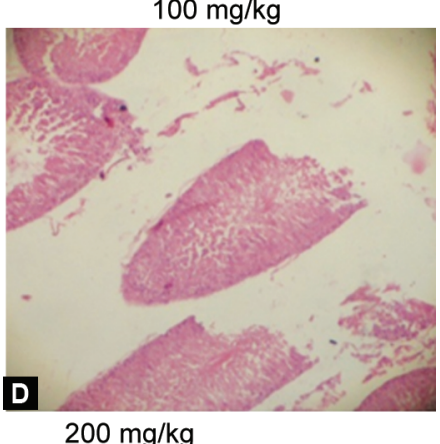
$100 \mathrm{mg} / \mathrm{kg}$

$200 \mathrm{mg} / \mathrm{kg}$

Figs 11A to D: Effect of ethanolic extract of Leonotis nepetifolia extract on testis

Table 7: Effect of ethanolic extract of Leonotis nepetifolia on fertility of male albino rats

\begin{tabular}{lllll}
\hline Groups & No. of male & $\begin{array}{l}\text { No. of } \\
\text { females }\end{array}$ & $\begin{array}{l}\text { No. of pregnant } \\
\text { females }\end{array}$ & $\begin{array}{l}\text { No. of } \\
\text { implantation }\end{array}$ \\
\hline Group I & 5 & 10 & $9 / 10$ & $9.350 \pm 0.231$ \\
Group II & 5 & 10 & $7 / 10$ & $6.864 \pm 0.576$ \\
Group III & 5 & 10 & $4 / 10$ & $4.548 \pm 1.623$ \\
Group IV & 5 & 10 & $2 / 10$ & $3.000 \pm 0.685$ \\
\hline
\end{tabular}

Values represent the mean \pm SD of the observation made on five rats in each group. Statistical analysis one way analysis of variance (ANOVA) with ad hoc testing least significant difference

evaluate the male reproductive toxicity of the $50 \%$ ethanolic extract of L. nepetifolia, which is an herbal medicine. In the male reproductive system, weight loss of the gonads, seminal vesicles, prostate gland, vas deferens as well as histology of gonads, biochemistry of testis, and epididymis are considered as the characterization of toxic agents that may cause fertility problems in the treated animals. ${ }^{19}$

The treatment of $L$. nepetifolia extracts $(100,150,200 \mathrm{mg} / \mathrm{kg} / \mathrm{bw}$ for 55 days) in rats suppresses the testicular and epididymal sperm counts and causes lesions in the seminiferous tubules. There is no effect on body weight and on general behavior of extract-treated rats. The reproductive organ weight decreased in all the treated groups when compared to the control groups. The treatment showed significant reduction in the serum concentration of $\mathrm{LH}$, $\mathrm{FSH}$, and testosterone level after the 55 days of treatment when compared to the control group. The primary step in the mechanism of the effects on testis induced by the L. nepetifolia extract was the suppression of LH. Absence of stimulation by LH causes Leydig cell dysfunction which results in the decline of testosterone secretion that is most responsible for the diminished spermatogenesis, and finally the total sperm count was reduced. The reduction in sperm motility in cauda epididymides is observed all treated animals when compared to the control group. Sperm morphology and viability are also decreased. ${ }^{20}$ The male antifertility activity of $L$. nepetifolia ethanolic extract at the dose level 100, 150, and $200 \mathrm{mg} / \mathrm{kg} / \mathrm{bw}$ has been proved by all said parameters.

The rise in cholesterol concentration of testis in ethanolic extract-treated male animals may represent the reduced conversion of cholesterol to testosterone. Glucose is the major substrate for metabolism in spermatids and spermatocyte in that testes. Glycogen levels were increased suggesting an inhibitory action of glycolysis in testis and epididymides. Cholesterol is the precursor for testosterone biosynthesis. Accumulation of cholesterol in the testis is the main evidence of antiandrogenic activity. Triglyceride is said to be energy source for spermatozoa, and its increase or decrease is suggestive of imbalanced synthesis. This will increase all treated groups when compared to the control group. ${ }^{21}$ A possible explanation for these observations could be attributed to the flavonoids contained in the plant extract. Flavonoids containing L. nepetifolia has been documented to possess antifertility and cytotoxic activity. ${ }^{22}$ Reactive oxygen species also involved DNA damage leading to mutations. Some antioxidant defenses are present in plants and their byproducts, mainly edible vegetables and spices, play a key role in human diet. The serum levels of ALT, AST, and ALP suggest that the treatment with the plant extract has decreased toxic effects when compared to the control rats. The antioxidant enzymes of catalases, SOD, GSH, glutathione peroxidase, and lipid peroxidation are also decreased in all treated groups when compared to the control groups. ${ }^{23}$ The result shows that the all doses $(100,150,200 \mathrm{mg} / \mathrm{kg} / \mathrm{bw})$ of $L$. nepetifolia ethanolic extract decreased the antioxidant activity. The treatment of crude extract of $L$. nepetifolia causes the alterations in male reproductive organ and suppression of fertility in males.

\section{Conclusion}

The present study concludes that the ethanolic extract of $L$. nepetifolia plant inhibited the fertility potential of male rats which is mediated by altered oxidative stress and decreased testosterone concentration. The daily administration of oral dose of $L$. nepetifolia ethanolic extract of 100, 150, and $200 \mathrm{mg} / \mathrm{kg}$ for a period of 55 days of in male animal (prior to contraceptive effects) did not elicit reproduction. The results achieved so far revealed that $L$. nepetifolia plant is orally effective safe and reversible, and thus meets out all the essential criteria of an ideal male contraceptive. The L. nepetifolia contain several efficacious subcomponents, and more studies have to emerge to explore the antifertility activity of other traditional herbs for the product management and mass application.

\section{ACKNOWLEDgments}

The authors thank Dean (Research), Sri Balaji Vidyapeeth (Deemed to be University), Puducherry for his constant guidance and support in the writing this article. The authors also thank the Instrumentation facility and Animal House Facility of the Department of Animal Science, Bharathidasan University extended under DST-FIST, DSTPURSE scheme.

\section{References}

1. Chauhan BS, Naved T. Herbal contraceptives: evaluation of antifertility potential of Hibiscus rosasinensis (Linn.). Asian J Pharm Clin Res 2018;11(11):36-41. DOI: 10.22159/ajpcr.2018.v11i11.20531. 
2. Karthik YP, Vrushabendra SB, Vishwanath KM. Evaluation of antifertility activities of leaves of Artabotrys hexapetalus (Linn. f.). Res J Pharmaceut, Biolog Chem Sci 2012;3(2):1121-1134.

3. Chandrakant J, Shetty AN, Mety S, Ali ML, Mathad P. In vivo Actiniopteris assessment of antifertility potential of pteridophytic plants: radiate Selaginella bryopteris (SW.) L. and (L.) baker in Swiss albino mice. Asian J Pharma Pharmacol 2019;5(1):152-158. DOI: 10.31024/ajpp.2019.5.1.22.

4. Umadevi M, Kumar PS, Bhowmik D, Duraivel S. Medicinal plants with potential antifertility activity. J Med Plant Stud 2013;1(1):26-33.

5. Dhawan NG, Khan AS, Srivastava P. A general appraisal of Leonotis nepetifolia (L) R. br: an essential medicinal plant. Bull Env Pharmacol Life Sci 2013;2(8):118-121.

6. Brinda P, Sasikala P, Purushothaman KK. Pharmacognostic studies on merugankizhangu. Bull Med Eth Bot Res 1981;3:84-96.

7. Zaneveld LJ, Polakoski KL. Collection and physical examination of the ejaculate. Techniq Human Androl 1977. 147-172.

8. Johnson LawrenceA, Maxwell WMC, Dobrinsky JR, Welch GR. Staining sperm for viability assessment. Reprod Domest Anim 2007;31(1): 37-47. DOI: 10.1111/j.1439-0531.1995.tb00004.x.

9. James SA, Bilbiss L, Muhammad BY. The effects of Catharanthus roseus (L) G. don 1838 aqueous leaf extract on some liver enzymes, serum proteins and vital organs. Sci World J 2007;2(1):5-9.

10. Reitman S, Frankel S. A colorimetric method for the determination of serum glutamic oxalacetic and glutamic pyruvic transaminases. Am J Clin Pathol 1957;28(1):56-63. DOI: 10.1093/ajcp/28.1.56.

11. King EJ, Armstrong AR. A convenient method for determining serum and bile phosphatase activity. CMAJ 1934;31(4):376.

12. Sinha AK. Colorimetric assay of catalase. Anal Biochem 1972;47(2): 389-394. DOI: 10.1016/0003-2697(72)90132-7.

13. Das S, Vasisht S, Das N, Srivastava LM, Dubey KK, Watal G. Correlation between total antioxidant status and lipid peroxidation in hypercholesterolemia. Curr Sci Bangalore 2000;78(4):486.
14. Rotruck JT, Pope AL, Ganther HE, Swanson AB, Hafeman DG, Hoekstra W. Selenium: biochemical role as a component of glutathione peroxidase. Science 1973;179(4073):588-590. DOI: 10.1126/ science.179.4073.588.

15. Ellman GL. Tissue sulfhydryl groups. Arch Biochem Biophys 1959;82(1):70-77. DOI: 10.1016/0003-9861(59)90090-6.

16. Friedewald WT, Levy RI, Fredrickson DS. Estimation of the concentration of low-density lipoprotein cholesterol in plasma, without use of the preparative ultracentrifuge. Clin Chem 1972;18(6):499-502. DOI: 10.1093/clinchem/18.6.499.

17. Kadalmani B, Girija R, Faridha A, Akbarsha MA. Male reproductive toxic effects of carbendazim: hitherto unreported targets in testis. Indian J Exp Biol 2002;40(1):40-44.

18. Sharma N, Jocob D. Antifertility investigation and toxicological screening of the petroleum ether extract of the leaves of Menthaarvensis L. in male albino mice. J Ethnopharmacol 2001;75(1):5-12. DOI: 10.1016/s0378-8741(00)00362-7.

19. Mathur N, Jain GC, Pandey G. Effect of Tecomastans leaves on the reproductive system of male albino rats. Int J Pharmacol 2010;6(1):152-156.

20. Mali PC, Ansari AS, Chaturvedi M. Antifertility effect of chronically administered Martyniaannua root extract on male rats. J Ethnopharmacol 2002;82(2-3):61-67. DOI: 10.1016/s03788741(02)00084-3.

21. Purohit A. Antifertility efficacy of Curcuma longa ( $50 \% \mathrm{E}$ to H extract) with special reference to serum biochemistry and fertility test. Anc Sci Life 1999;18(3-4):192.

22. Ajayi AF, Akhigbe RE. Antifertility activity of Cryptolepis sanguinolento leaf ethanolic extract in male rats. J Hum Reprod Sci 2012;5(1):43. DOI: 10.4103/0974-1208.97799.

23. Gupta PC. A preliminary study on effects of leaf extract of Ficus benghalensis (Linn.) on spermatogenesis and fertility in albino mice. Int J Pharm Tech Res 2012;4(1):226-232. 